\title{
Non-pharmacological treatment of hypertension
}

\author{
By Norman M. Kaplan, Department of Internal Medicine, University of Texas, \\ Southwestern Medical School, Dallas, Texas 75235-9030, USA
}

Non-drug therapy of hypertension is needed more than ever but its application remains much below optimum. The greater need reflects the much larger population of asymptomatic people being identified as mildly hypertensive in whom, if non-drug therapy were even moderately effective, the pressures could be lowered to a level deemed safe without the need for pills. The need is heightened by the increasing recognition that antihypertensive drug therapy, as it has been applied in six large clinical trials, has not clearly provided protection against coronary heart disease (Kaplan, 1986). Although this failure may reflect a misguided attempt to reverse a process that is little related to high blood pressure alone, it may also reflect biochemical abnormalities induced by the drugs (Kuller et al. 1986). Diuretics and $\beta$-blockers, the two most widely used drugs today, are particularly suspect for their induction of unfavourable changes in blood lipids (Weidmann et al. 1985).

The less than optimum use of non-drug therapy in large part reflects two interrelated factors: first, many practitioners doubt their effectiveness, partly because so few properly controlled trials have been done; second, many patients are unwilling to use them, without ongoing encouragement from many of their physicians on the one hand, but with too many stringent demands by some practitioners who prescribe them on the other. For both practitioners and patients to adopt these non-drug therapies, the demonstration that they will lower the blood pressure without risk or undue interference with the quality of life should be all that is required. To expect proof that they will not only lower blood pressure but also prevent cardiovascular morbidity and mortality is unrealistic and unnecessary. Despite carefully controlled 5- to 10-year trials involving over 30000 patients with the use of drugs that are much more potent than any non-drug therapy, we still lack proof that drugs will protect against coronary heart disease. To demand that non-drug therapy, less potent and much more difficult to monitor, must do more than lower the blood pressure before accepting it as worth while, then, immediately negates its use for the treatment of hypertension.

I will present a small sample of the recent evidence that various non-drug therapies that can be implemented without risk or undue interference with the quality of life will lower blood pressure. More evidence is available elsewhere (Kaplan, 1985). Many non-drug therapies will also improve overall cardiovascular risk in other ways; e.g. lowering blood lipids, reducing body-weight, improving glucose tolerance. These extra advantages need to be gained by patients with hypertension because they tend to carry more of these other risk burdens than do non-hypertensive people. Untreated hypertensives have been found to have higher prevalences of hypercholesterolaemia (MacMahon \& Macdonald, 1986), obesity (Velasquez \& Hoffmann, 1985) and glucose intolerance (Modan et al. 1985). In addition, their hypertension may be related to high levels of alcohol consumption (Jackson et al. 1985) and associated with the Type A behaviour pattern (Matthews \& Haynes, 1986), all potential targets for broad-based non-drug therapy. Thus, even if such therapy does little for the blood pressure, it may do more for the overall cardiovascular risk status of the patient, which after all is the major goal of medical management. 


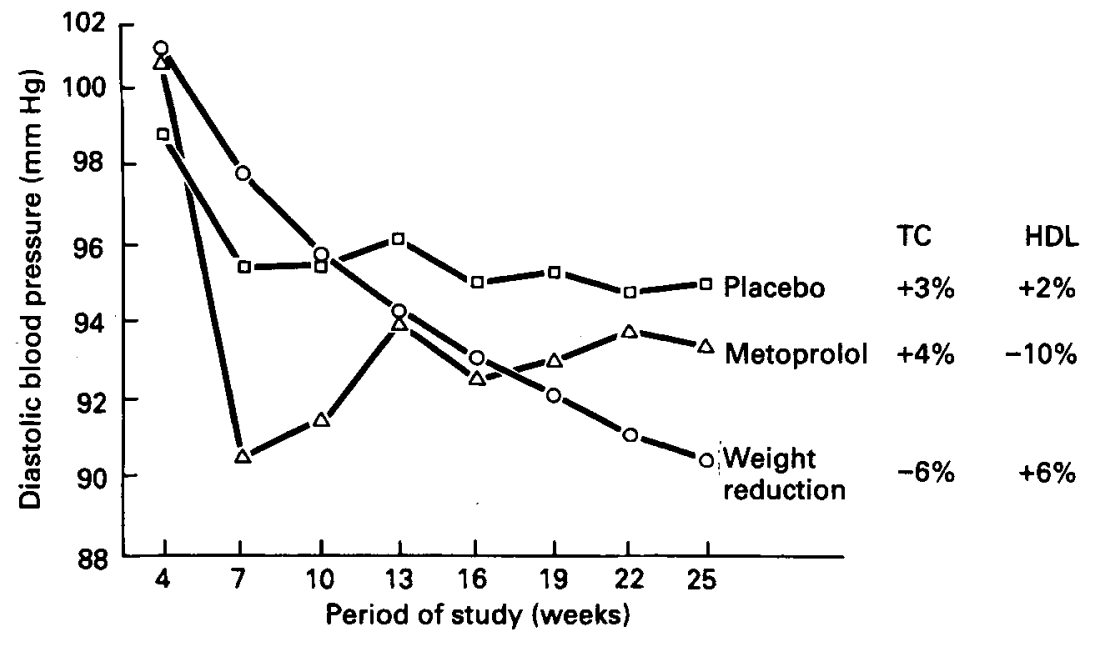

Fig. 1. The changes in diastolic blood pressure, total cholesterol (TC) and high-density-lipoprotein (HDL) in fifty-six young, obese hypertensives who were randomly assigned to placebo ( $\square$ ), $200 \mathrm{mg}$ metoprolol/d $(\Delta)$, or weight reduction by a decrease of $4.18 \mathrm{MJ}(1000 \mathrm{kcal}) / \mathrm{d}(\mathrm{O})$ for 21 weeks. The weight reduction resulted in a $7.4 \mathrm{~kg}$ loss of body-weight (values from MacMahon et al. 1985).

\section{Weight reduction}

The loss of $7.4 \mathrm{~kg}$ over a 21 -week period by a group of obese hypertensives resulted in a significant reduction in blood pressure and left ventricular hypertrophy, along with an improvement in blood lipids (MacMahon et al. 1985, 1986) (Fig. 1). Those randomly assigned to therapy with a $\beta$-blocker or placebo did less well. This study stands as a properly controlled demonstration of the value of feasible weight reduction.

\section{Sodium restriction}

Most controlled studies of moderate Na restriction, down to $2 \mathrm{~g} / \mathrm{d}$, $(88 \mathrm{~mm})$, have shown a modest fall in blood pressure (MacGregor, 1985). Some fail to find an effect, partly because their patients had minimally elevated pressures: as is true of all effective therapies for hypertension, the higher the starting pressure, the greater the fall. Others have used too-rigid $\mathrm{Na}$ restriction, which, by activating the renin-aldosterone and sympathetic nervous systems, may be counterproductive. Beyond methodological problems, only a portion of the overall hypertensive population are ' $\mathrm{Na}$ sensitive', i.e. will have a significant fall in pressure with $\mathrm{Na}$ deprivation or a significant rise with $\mathrm{Na}$ loading (Bittle et al. 1985).

Nonetheless, moderate $\mathrm{Na}$ restriction is easy to accomplish and totally without risk. Those who have raised the spectre of paradoxical rises in pressure or stunting of growth (Brown et al. 1984) misuse the experimental evidence. The studies in rats they quote involved the use of 1:100 to 1:400 the usual intake of $\mathrm{Na}$ in the rat diet, hardly applicable to the human experience. Although moderate Na restriction will likely lower pressure on its own, it will also likely potentiate the effect of various antihypertensive drugs, with the possible exception of calcium-entry blockers (Morgan et al. 1986).

\section{Potassium supplementation}

When fresh foods are used instead of processed forms to reduce dietary $\mathrm{Na}$ intake, $\mathrm{K}$ intake automatically increases. Therefore some of the benefits ascribed to $\mathrm{Na}$ restriction 
may reflect increased $\mathrm{K}$ intake. In addition, a small fall in blood pressure has been noted in some studies of supplemental K of 60-100 mmol/d (Kaplan, 1985). We observed a somewhat greater effect, with an average fall in mean blood pressure of $5.5 \mathrm{~mm} \mathrm{Hg}$, in nineteen hypokalaemic hypertensives given $60 \mathrm{mmol}$ supplemental $\mathrm{K} / \mathrm{d}$ for 6 weeks in a placebo-controlled trial (Kaplan et al. 1985).

\section{Magnesium supplementation}

No antihypertensive effect has been documented with $\mathrm{Mg}$ supplements but the persistence of hypomagnesaemia may preclude the replenishment of intracellular $\mathrm{K}$ depletion (Whang et al. 1985).

\section{Ca supplementation}

Compared with non-hypertensives, some hypertensives have been found to ingest less $\mathrm{Ca}$, others to leak $\mathrm{Ca}$ into the urine, and to have slightly lower plasma ionized $\mathrm{Ca}$ levels (McCarron, 1985). The administration of $1000 \mathrm{mg} \mathrm{Ca} / \mathrm{d}$ for 8 weeks has been found to be accompanied by an average $5.6 \mathrm{~mm} \mathrm{Hg}$ fall in standing systolic blood pressure (McCarron \& Morris, 1985). However, one-third of patients had rises in blood pressure during the trial and the investigators were unable to separate, with a variety of measurements, those who responded well from those who responded adversely.

Since higher intracellular $\mathrm{Ca}$ is widely thought to be somehow responsible for hypertension, the use of $\mathrm{Ca}$ to lower blood pressure seems illogical. There is little theoretical or experimental support for this approach. Until it is shown clearly to be effective and not potentially harmful, Ca supplements should not be used to treat hypertension.

\section{Other dietary changes}

The addition of fibre to the diet and the deletion of foods with large amounts of saturated fat may also produce an antihypertensive effect (Dodson et al. 1985). Such changes may be responsible for the lower blood pressure observed during intake of a lacto-ovo-vegetarian diet (Rouse et al. 1986).

In non-coffee drinkers, the ingestion of caffeine equivalent to the amount in three cups of coffee will raise the blood pressure, probably by activation of the sympathetic nervous system (Robertson et al. 1984). However, chronic caffeine ingestion is not associated with significant rises in blood pressure because of tolerance to the haemodynamic effects.

\section{Moderation of alcohol}

Moderate alcohol consumption, less than $30 \mathrm{~g}$ ethanol/d, does not increase the prevalence of hypertension. Heavier drinking clearly exerts a pressor effect that makes alcohol abuse the most common cause of reversible hypertension (Jackson et al. 1985). One to two portions of alcohol-containing beverages/d, containing $15-30 \mathrm{~g}$ ethanol, need not be prohibited, particularly since fewer coronary events have been noted in those who consume that amount (Colditz et al. 1985).

\section{Isotonic exercise}

In well-controlled studies, regular isotonic exercise has resulted in a $5-10 \mathrm{~mm} \mathrm{Hg}$ reduction in blood pressure, accompanied by and likely related to a fall in sympathetic nervous activity (Duncan $e t$ al. 1985; Jennings $e$ t al. 1986). The antihypersensitive effect extends beyond the loss of weight that may accompany regular exercise. 


\section{Relaxation techniques}

Various forms of relaxation-transcendental meditation, yoga, biofeedback, psychotherapy-have been shown to reduce the blood pressure of some hypertensives, at least transiently (Health and Public Policy Committee, American College of Physicians, 1985). Most studies have been poorly controlled but an impressive effect was observed in a well-controlled study by Patel et al. (1981). They randomly assigned half a group of newly identified hypertensives to a biofeedback-aided relaxation programme for 8 weeks, while the other half served as controls, being seen as often but not given the relaxation therapy. Both at the end of the active programme and 6 months later (during which time the subjects had been asked to continue to practise relaxation but had not been seen), blood pressures among the treated group were significantly lowered.

\section{The potential of non-drug therapy}

Part of the antihypertensive effect reported with non-drug therapies may be attributable to the non-specific fall in blood pressure so often seen when repeated readings are taken. Such decreases may reflect a statistical regression towards the mean, a placebo effect, or a relief of anxiety and stress with time. The same phenomenon is probably also responsible for much of the initial response to drug therapy, so that success may be attributed to both drugs and non-drugs when it is deserved by neither.

Few long-term studies of the effectiveness of non-drug therapies have been carried out. Two are now in progress, involving former participants in the Hypertension Detection and Follow-up Trial who have been taken off their antihypertensive therapy and followed on various non-drug regimens, including Na restriction or weight reduction, to see how many remain normotensive compared with those on no therapy (Langford et al. 1985; Stamler et al. 1985). Preliminary results show that about one-third more remain normotensive on non-drug therapy than on no therapy.

Whether such success can be achieved by individual practitioners is uncertain. However, since help is available, including various educational materials for patients, professional assistants such as dietitians and psychologists, and groups organized for weight reduction, exercise and relaxation therapies, the effort seems both increasingly easy and likely to be successful in lowering blood pressure.

\section{REFERENCES}

Bittle, C. C. Jr, Molina, D. J. \& Bartter, F. C. (1985). Hypertension 7, 989-994.

Brown, J. J., Lever, A. F., Robertson, J. I. S., Semple, P. F., Bing, R. F., Heagerty, A. M., Swales, J. D., Thurston, H., Leddingham, J. G. G., Laragh, J. H., Hansson, L., Nicholls, M. G. \& Espiner, A. E. (1984). Lancet ii, 456.

Colditz, G. A., Branch, L. G., Lipnick, R. J., Willett, W. C., Rosner, B., Posner, B. \& Hennekens, C. H. (1985). American Heart Journal 109, 886-889.

Dodson, P. M., Pacy, P. J. \& Cox, E. V. (1985). Human Nutrition: Clinical Nutrition 39C, 213-220.

Duncan, J. J., Farr, J. E., Upton, S. J., Hagan, R. D., Oglesby, M. E. \& Blair, S. N. (1985). Journal of the American Medical Association 254, 2609-2613.

Health and Public Policy Committee, American College of Physicians (1985). Annals of Internal Medicine 102, 709-715.

Jackson, R., Stewart, A., Beaglehole, R. \& Scragg, R. (1985). American Journal of Epidemiology 122, 1037-1044.

Jennings, G., Nelson, L., Nestel, P., Esler, M., Korner, P., Burton, D. \& Bazelmans, J. (1986). Circulation $73,30-40$.

Kaplan, N. M. (1985). Annals of Internal Medicine 102, 359-373. 
Kaplan, N. M. (1986). Clinical Hypertension, 4th ed. Baltimore: Williams and Wilkins.

Kaplan, N. M., Carnegie, A., Raskin, P., Heller, J. A. \& Simmons, M. (1985). New England Journal of Medicine 312, 746-749.

Kuller, L. H., Hulley, S. B., Cohen, J. D. \& Neaton, J. (1986). Circulation 73, 114-123.

Langford, H. G., Blaufox, M. D., Oberman, A., Hawkins, C. M., Curb, J. D., Cutter, G. R., WassertheilSmoller, S., Pressel, S., Babcock, C., Abernethy, J. D., Hotchkiss, J. \& Tyler, M. (1985). Journal of the American Medical Association 253, 657-664.

McCarron, D. A. (1985). Hypertension 7, 607-627.

McCarron, D. A. \& Morris, C. D. (1985). Annals of Internal Medicine 103, 825-831.

MacGregor, G. A. (1985). Hypertension 7, 628-637.

MacMahon, S. W. \& Macdonald, G. J. (1986). American Journal of Medicine 80, Suppl. 2A, $40-47$.

MacMahon, S. W., Macdonald, G. J., Bernstein, L., Andrews, G. \& Blacket, R. B. (1985). Lancet i, 1233-1236.

MacMahon, S. W., Wilcken, D. E. L. \& Macdonald, G. J. (1986). New England Journal of Medicine 314, 334-339.

Matthews, K. A. \& Haynes, S. G. (1986). American Journal of Epidemiology 123, 923-960.

Modan, M., Halkin, H., Almog, S., Lusky, A., Eshkol, A., Shefi, M., Shitrit, A. \& Fuchs, Z. (1985). Journal of Clinical Investigation 75, 809-817.

Morgan, T., Anderson, A., Wilson, D., Myers, J., Murphy, J. \& Nowson, C. (1986). Lancet i, 793.

Patel, C. H., Marmot, M. G. \& Terry, D. J. (1981). British Medical Journal 282, 2005-2008.

Robertson, D., Hollister, A. S., Kincaid, D., Workman, R., Goldberg, M. R., Tung, C. S. \& Smith, B. (1984). American Journal of Medicine 77, 54-60.

Rouse, I. L., Beilin, L. J., Mahoney, D. P., Margetts, B. M., Armstrong, B. K., Record, S. J., Vandongen, R. \& Barden, A. (1986). Journal of Hypertension 4, 241-250.

Stamler, R., Stamler, J., Grimm, R., Dyer, A., Gosch, F. C., Berman, R., Elmer, P., Fishman, J., Van Hell, N., Civinelli, J. \& Hoeksema, R. (1985). Preventive Medicine 14, 336-345.

Velasquez, M. T. \& Hoffmann, R. G. (1985). Quarterly Journal of Medicine 54, 205-212.

Weidmann, P., Uehlinger, D. E. \& Gerber, A. (1985). Journal of Hypertension 3, 297-306.

Whang, R., Flink, E. B., Dyckner, T., Wester, P. O., Aikawa, J. K. \& Ryan, M. P. (1985). Archives of Internal Medicine 145, 1686-1689. 